\title{
microRNA-625 inhibits tumorigenicity by suppressing proliferation, migration and invasion in malignant melanoma
}

\author{
Wei Fang ${ }^{1,3, *}$, Yibin Fan' ${ }^{6, *}$, Zhenzong Fa ${ }^{1, *}$, Jinhua $\mathrm{Xu}^{3}$, Hongyu $\mathrm{Yu}^{4}$, Pu $\mathrm{Li}^{5}$, Julin Gu${ }^{1,2}$ \\ ${ }^{1}$ Shanghai Key Laboratory of Molecular Medical Mycology, Department of Dermatology and Venereology, Changzheng \\ Hospital, Second Military Medical University, Shanghai, 200003, China \\ ${ }^{2}$ Department of Dermatology, Eastern Hepatobiliary Surgery Hospital, Second Military Medical University, Shanghai, 201805 \\ China \\ ${ }^{3}$ Department of Dermatology, Huashan Hospital, Fudan University, Shanghai, 200040, China \\ ${ }^{4}$ Department of Pathology, Changzheng Hospital, Second Military Medical University, Shanghai, 200003, China \\ ${ }^{5}$ Department of Pediatrics, Ruijin Hospital and Ruijin Hospital North, School of Medicine, Shanghai Jiao Tong University, \\ Shanghai, 200025, People's Republic of China \\ ${ }^{6}$ Department of Dermatology, Zhejiang Provincial People's Hospital, Hangzhou, Zhejiang, 310014, China \\ *These authors have contributed equally to this work \\ Correspondence to: Pu Li, email: leerockygood@yahoo.com \\ Julin Gu, email: wujgjl@126.com
}

Keywords: malignant melanoma, miR-625, tumorigenesis, SOX2

Received: July 29, $2016 \quad$ Accepted: December 12, 2016

Published: January 18, 2017

\section{ABSTRACT}

Dysregulated microRNA ( $\mathrm{miR}$ )-625 expression has been observed in several kinds of cancer. MicroRNAs are important factors in the development and progression of malignant melanoma, though the clinical significance and function of miR-625 in human malignant melanoma remain unclear. Levels of miR-625 expression were therefore determined in $\mathbf{3 6}$ pairs of malignant melanoma and adjacent non-tumor tissue using qPCR. The effects of miR-625 dysregulation on malignant melanoma cell proliferation, wound healing, migration and invasion in vitro and tumorigenicity in vivo were investigated using CCK-8, transwell assays, and a nude mouse subcutaneous tumor model. Bioinformatics analysis and luciferase reporter system were used to predict and confirm the target gene of miR-625. miR-625 levels were frequently decreased in malignant melanoma. Ectopic expression of miR-625 suppressed proliferation, wound healing, migration, and tumorgenicity in malignant melanoma. Moreover, miR-625 acted, at least in part, by suppressing potential target SOX2. These results show that miR-625 is a tumor suppressor that inhibits the development and progression of malignant melanoma, which suggests miR-625 is potentially a new diagnostic marker and therapeutic target of malignant melanoma.

\section{INTRODUCTION}

Malignant melanoma, a skin cancer that arises from malignant transformation of melanocytes, is highly aggressive and metastatic [1]. Patient prognosis is poor and the 5 -year survival rate is less than $15 \%[2,3]$. The malignant melanocytes show aberrant proliferation, resistance to apoptosis, and highly invasive potential and motility capacity, which are important biological characteristics in the aggressive clinical course of the metastatic disease $[4,5]$. Researchers have conducted a number of studies of malignant melanoma [6], but the complicated molecular mechanism of malignant melanoma development and progression requires us to make further explorations.

MicroRNAs (miRNAs) are noncoding small RNAs 18 to 22 nucleotides in length that regulate gene expression at the post-transcriptional level, and they influence many biological signaling pathways [7]. miRNAs bind to seed sequences in the 3'-untranslated 
regions (3'-UTRs) of their targets and induce mRNA degradation or translational suppression [8]. Many studies report significant deregulation of microRNAs expression profiling between tumor cells and cells derived from normal tissue, indicating that miRNAs function as either oncogenes or tumor suppressors in various cancers [9-11].

miR-625 deregulation has been detected in many cancers, including breast cancer [12], colorectal carcinoma [13], hepatocellular carcinoma [14], squamous cell carcinoma [15], and gastric cancer [16]. These studies show that miR-625 is frequently deregulated in tumor tissue or cells, and the decreased expression of miR-625 correlated with the invasiveness and metastasis predict high malignancy and poor prognosis. However, the function of miR-625 in malignant melanoma is largely unknown. A recent study indicates that miR-625 is one of the miRNAs that are downregulated in highly invasive malignant melanoma cells [17].

Therefore, we focused on miR-625 to further investigate its association with malignant melanoma and investigate the function and molecular mechanism of miR625 in the progression of malignant melanoma and to explore the practicality of using miR-625 as a diagnostic marker and therapeutic target.

\section{RESULTS}

\section{miR-625 is downregulated in human malignant melanoma}

Through analysis of the related microRNA array data, we found that the abnormal expression of miR625 is associated with malignancy or the development process in many types of tumors (Figure 1A) $[14,16,18$, 19]], and it was one of downregulated microRNAs in the highly invasive melanoma cell lines [17]. However, the functions and molecular mechanisms of miR-625 have not been investigated in malignant melanoma. To examine the expression levels of miR-625 in malignant melanoma tissue and normal tissue, we performed qRT-PCR analysis on 36 malignant melanoma samples. Results suggested that reduction of miR-625 occurs in approximately $75 \%$ of human malignant melanoma (27/36 samples, Figure 1B), and the average relative expression level of miR-625 is significantly downregulated in tumor tissue compared with the non-tumor tissue (Figure $1 \mathrm{C},{ }^{*} P<0.05$ ).

\section{miR-625 inhibits cell proliferation and clonogenicity of malignant melanoma cells in vitro}

Because miR-625 is significantly downregulated in malignant melanoma, it might function as a tumor suppressor. Therefore, we determined whether deregulation of miR-625 in malignant melanoma cells correlates with cell proliferation. To investigate the function of miR-625, mimics or anti-sense oligonucleotides and control oligonucleotides were transfected into malignant melanoma cells A375 and M14, respectively. We examined the effects of miR-625 on cell growth by water-soluble tetrazolium salt (WST) cell-growth assay. The results showed that cell growth was inhibited in the group transfected with miR-625 mimics compared with the cells transfected with control mimics, and the cell growth was promoted by anti-miR-625 compared with the anti-negative control (NC) oligos. $(* P$ $<0.05, * * P<0.01$, Figure 2A and 2B).

To further characterize the effect of miR- 625 on cell proliferation, a plate colony formation assay was performed. The result showed that the number of colonies from malignant melanoma cells transfected with miR-625 mimics was significantly fewer than the number from the control group, and the number of colonies from cells transfected with anti-miR-625 was higher compared with the control group transfected with anti-NC (Figure 2C and 2D). The number of colonies from $\mathrm{A} 375^{\mathrm{miR}-625}$ and M14 ${ }^{\text {miR-625 }}$ cells were fewer than the number of colonies from control groups $\mathrm{A} 375^{\mathrm{NC} \text { mimics }}$ and $\mathrm{M} 14^{\mathrm{NC} \text { mimics }}$, and the
A

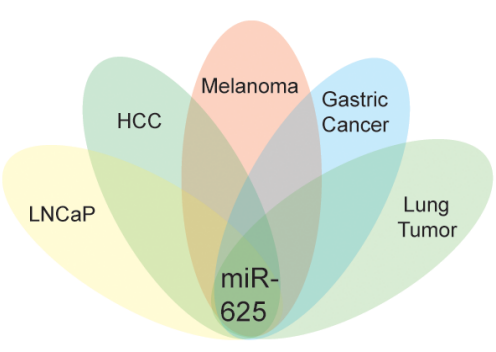

B

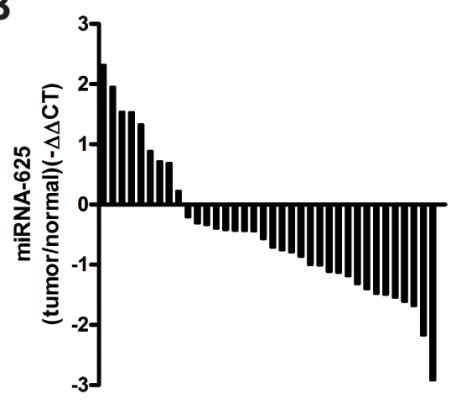

C

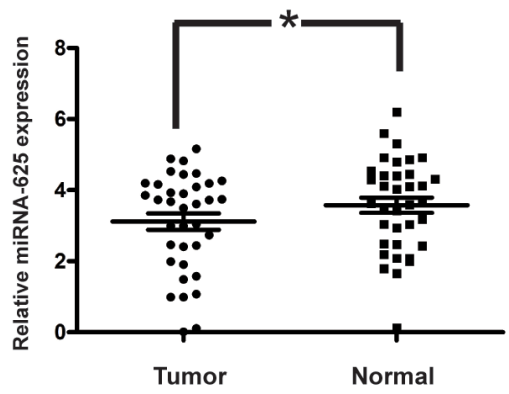

Figure 1: miR-625 is downregulated in malignant melanoma tissues. A. Overview of cluster analysis of deregulated microRNAs in several common tumors. miR-625 is an overlapping candidate. B. miR-625 was detected in melanoma tissues. The data are shown as ${ }^{-\Delta \Lambda}$ CT values. C. Relative expression of miR-625 in malignant melanoma patients' tumor tissues compared with normal tissues. Data are shown as mean $\pm \operatorname{SEM}(* P<0.05)$. 
number of colonies from A375 anti-miR-625 and M14 ${ }^{\text {anti-miR-625 }}$ cells were higher than the number of colonies from control groups $\mathrm{A} 375^{\mathrm{NC} \text { mimics }}$ and $\mathrm{M} 14^{\mathrm{NC} \text { mimics }}\left({ }^{*} P<0.05, * * P<\right.$ 0.01 , Figure $2 \mathrm{E}$ and $2 \mathrm{~F}$ ). These findings indicate that miR625 inhibits proliferation and colony-forming ability of malignant melanoma cells.

\section{miR-625 inhibits wound-healing ability of malignant melanoma cells}

We tested whether miR-625 has an impact on the movement ability of malignant melanoma cells by wound-healing assay. The results are shown in Figure
$3 \mathrm{~A}$. Restoration of the miR-625 overexpressing cell line A $375^{\text {miR-625 }}$ slowly closed the scratch wounds compared with the control group 36 hours after scratching. In contrast, the $\mathrm{A} 375^{\text {anti-miR-625 }}$ cells were significantly efficient in wound healing (Figure 3B). The results in the M14 cell groups were consistent with the above data (Figure 3C and 3D).

\section{miR-625 suppresses migration and invasion of malignant melanoma cells in vitro}

To further assess the influence of miR-625 on malignant melanoma cells, we explored its effects
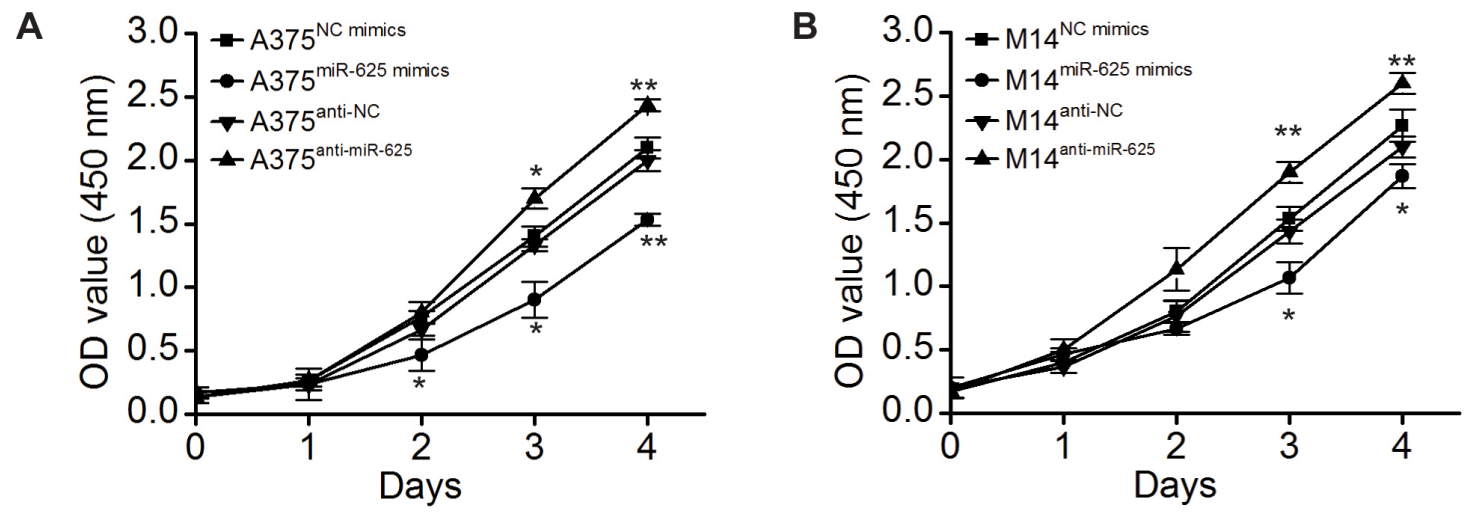

C

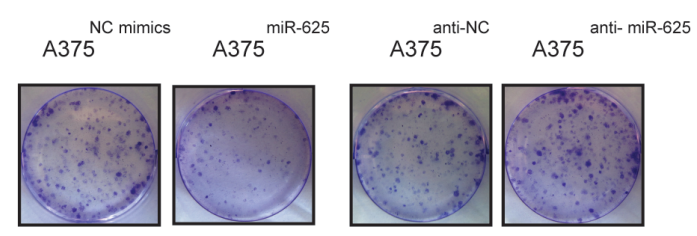

D
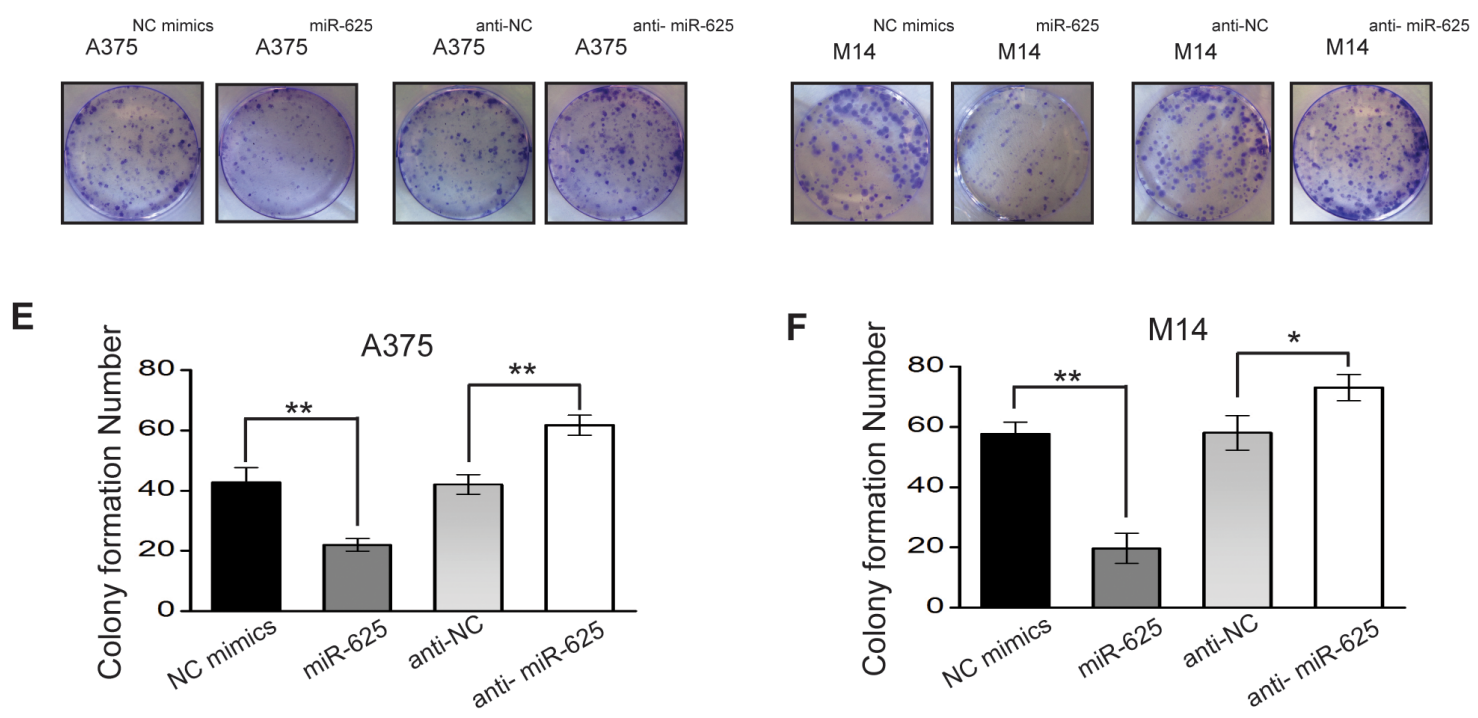

Figure 2: The effect of miR-625 on the proliferation of malignant melanoma cells. A. Cell proliferation was measured by the WST assay. A375 cells were transfected with miR-625 mimics, NC mimics, anti-625, or anti-NC at a final concentration of $100 \mathrm{nM}$, at 24 hours after transfection. The WST assay was performed every 24 hours for 4 days. Results are means of three independent experiments \pm S.D. $\left(* P<0.05,{ }^{*} P<0.01\right)$. B. M14 cells were transfected with miR-625 mimics, NC mimics, anti-625, or anti-NC at a final concentration of $100 \mathrm{nM}$, at 24 hours after transfection. The WST assay was performed every 24 hours for 4 days. Results are means of three independent experiments \pm S.D. $(* P<0.05, * * P<0.01)$. C. The effect of miR-625 on cell proliferation was evaluated by the plate colony formation assay. A375 cells were transfected with miR-625 mimics, NC mimics, anti-625, or anti-NC, and then seeded onto 6-well plates. The number of colonies was counted on the 14 th day after seeding. D. M14 cells were transfected with miR-625 mimics, NC mimics, anti-625, or anti$\mathrm{NC}$, and then seeded onto 6-well plates. The number of colonies was counted on the 14 th day after seeding. E-F. Colonies containing 50 or more cells were counted. Results are means of three independent experiments \pm S.D. $(* P<0.05, * * P<0.01)$. 
on cell migration and invasion, a key factor in tumor progression and metastasis. The results showed that ectopic expression of miR-625 significantly suppressed migration and invasion of malignant melanoma cells, whereas knockdown of miR-625 by anti-sense oligos significantly enhanced migration and invasion. As shown in Figure 4, the number of migratory and invasive A375 cells transfected with miR-625 mimics was significantly less than the control group, whereas the number of A375 cells transfected with anti-miR-625 was higher than the control group $(* * P<0.01$, Figure $4 \mathrm{~A}$ and $4 \mathrm{~B})$, and the results of the M14 cell groups are also consistent. ( $* P<$ 0.05 , Figure $4 \mathrm{C}$ and 4D). Our data show that miR-625 is an important factor in the migration and invasion ability of malignant melanoma cells.

\section{miR-625 suppresses tumorigenicity of malignant melanoma cells in nude mice in vivo}

We next validated whether ectopic expression of miR-625 influences the tumor growth of malignant melanoma cells in vivo. To explore the contribution of miR-625 in vivo, we carried out mouse xenograft models. Malignant melanoma cells A375 transfected with miR625 mimics or control mimics were selected and injected subcutaneously into nude mice, and the tumor formation was monitored. As shown in the Figure $5 \mathrm{~A}-5 \mathrm{C}$, the tumors grew progressively in the control group, but were suppressed in the miR-625 ectopic expression group. These mice were euthanized 5 weeks after the injection, and the tumor weights and volume were measured (Figure 5D and 5C). Strikingly, the tumor volumes and weights in the $\mathrm{A} 375^{\mathrm{miR}-625}$ group were significantly less than the volumes and weights in the control group. Thus, these results indicate that miR-625 suppresses tumorigenesis of malignant melanoma cells in vivo.

\section{miR-625 targets the $3^{\prime}$-UTR of $S O X 2$}

To identify how miR-625 functions in malignant melanoma cells, computational prediction of miR-625 targets was performed. We searched putative targets using bioinformatics tools (e.g., TargetScan, Microrna. org, and RNAhybrid) [20-24]. The genes predicted by all the programs were considered candidate targets of miR625. Among all the hits, sex determining region Y (SRY)box 2 (SOX2) caught our attention (Figure 6A and 6B). We checked the expression levels of SOX2 in malignant melanoma tissue and normal tissue. The result showed that the average relative expression level of miR-625 was significantly upregulated in tumor tissue compared with non-tumor tissue (Figure 6C). Moreover, $S O X 2$ expression
A
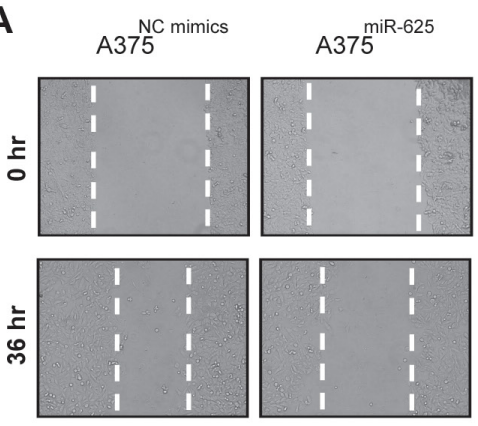

C
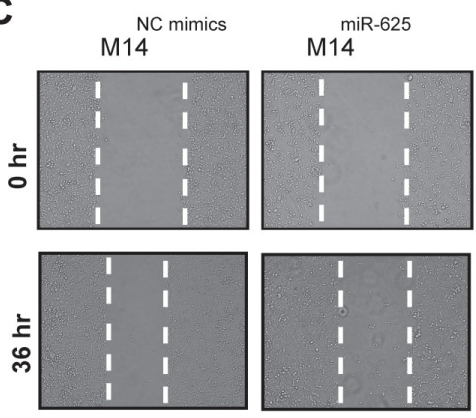
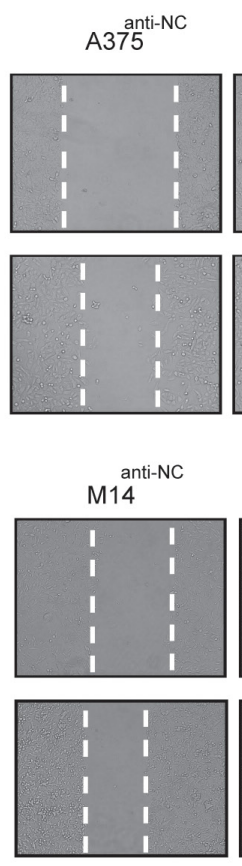

A375 $5^{\text {anti- miR-625 }}$
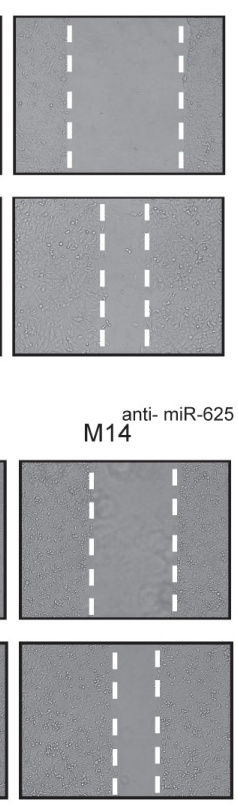

B
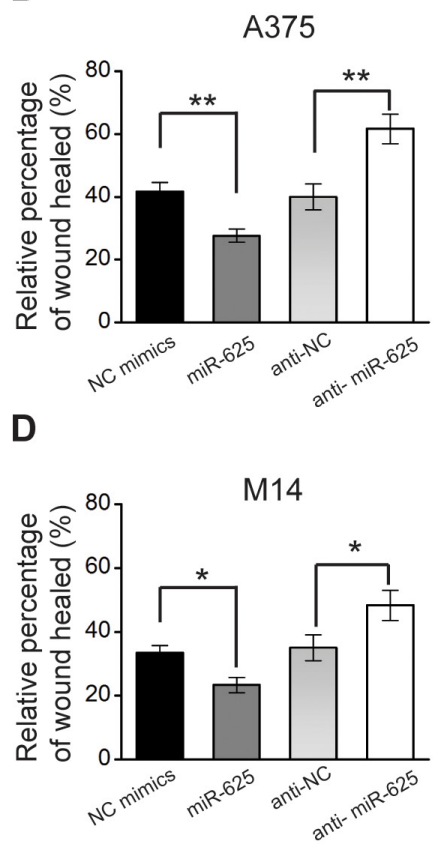

Figure 3: miR-625 inhibits scratch wound-healing ability of malignant melanoma cells. A. Movement ability of A375 mimics, A375 ${ }^{\text {miR-625 }}, \mathrm{A} 375^{\text {anti-NC }}$, or A375 ${ }^{\text {anti-miR-625 }}$ cell lines was detected by scratch wound-healing assays. B. Cell migration is quantified as a percentage of wound-healed area. Data represent mean \pm SD (**P<0.01). C. Movement ability of M14 ${ }^{\mathrm{NC} \text { mimics }}, \mathrm{M}^{\mathrm{miR}-625}$, M14 ${ }^{\text {anti-NC }}$, or M14 ${ }^{\text {anti-miR-625 }}$ cell lines was detected by scratch wound-healing assays. D. Cell migration is quantified as percentage of wound-healed area. Data represent mean $\pm \mathrm{SD}(* P<0.05)$. 
A

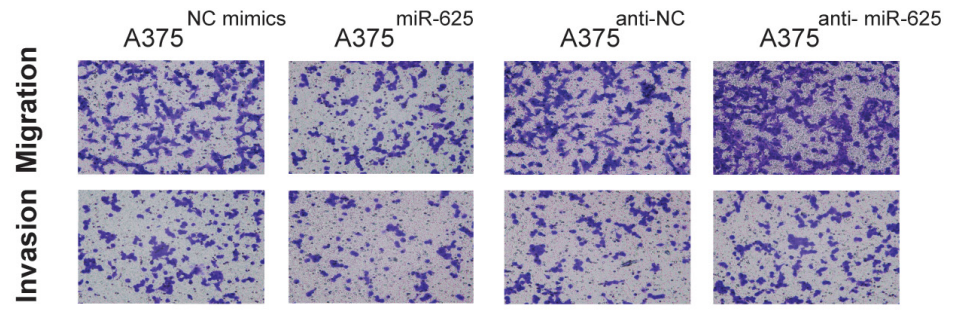

C
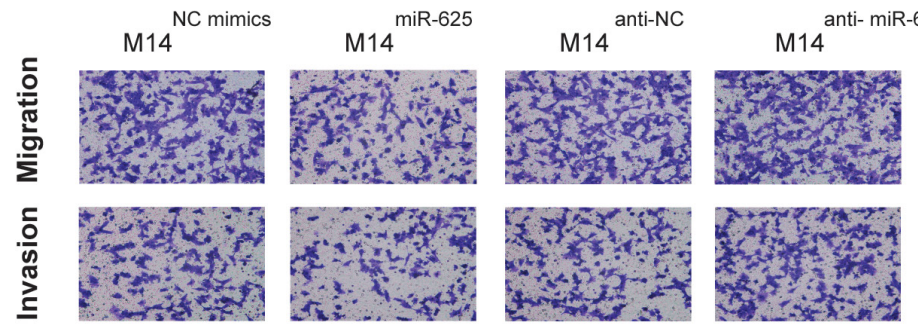

B

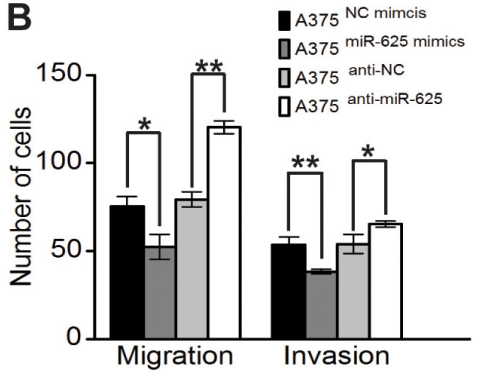

D

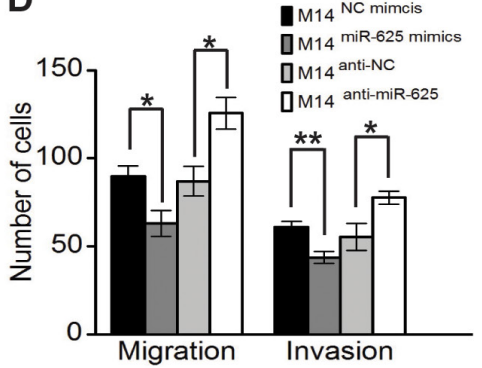

Figure 4: miR-625 inhibits migration and invasion of malignant melanoma cells. A. Representative photographs of migratory or invasive $\mathrm{A} 375^{\mathrm{NC} \text { mimics }}, \mathrm{A} 375^{\text {miR-625 }}$, $\mathrm{A} 375^{\text {anti-NC }}$, or $\mathrm{A} 375^{\text {anti-miR-625 }}$ cells on the membrane (magnification, $100 \times$ ). B. Average number of migratory or invasive $\mathrm{A} 375^{\mathrm{NC} \text { mimics }}, \mathrm{A} 375^{\text {miR-625 }}$, A375 ${ }^{\text {anti-NC }}$, or A375 anti-miR-625 cells. $\left({ }^{*} P<0.05,{ }^{*} P<0.01\right)$. C. Representative photographs of migratory or invasive M14 $4^{\mathrm{NC} \text { mimics }}$, M14 ${ }^{\text {miR-625 }}$, M14 ${ }^{\text {anti-NC}}$, or M14 $4^{\text {anti-miR-625 }}$ cells on the membrane (magnification, 100 $\times$ ). D. Average number of migratory or invasive M14 ${ }^{\mathrm{NC} \text { mimics }}, \mathrm{M} 14^{\text {miR-625}}, \mathrm{M} 14^{\text {anti-NC }}$, or M14 ${ }^{\text {anti-miR-625 }}$ cells $\left({ }^{*} P<0.05,{ }^{*} P<0.01\right)$. The data represent the mean \pm S.D. of three independent experiments.

A

$\mathrm{A} 375^{\text {Control }}$

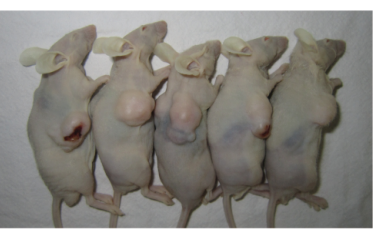

B A $375^{\text {miR-625 }}$

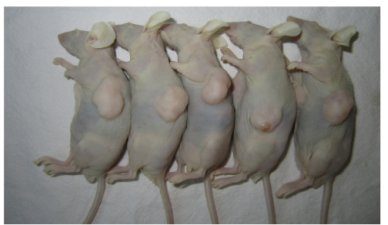

D

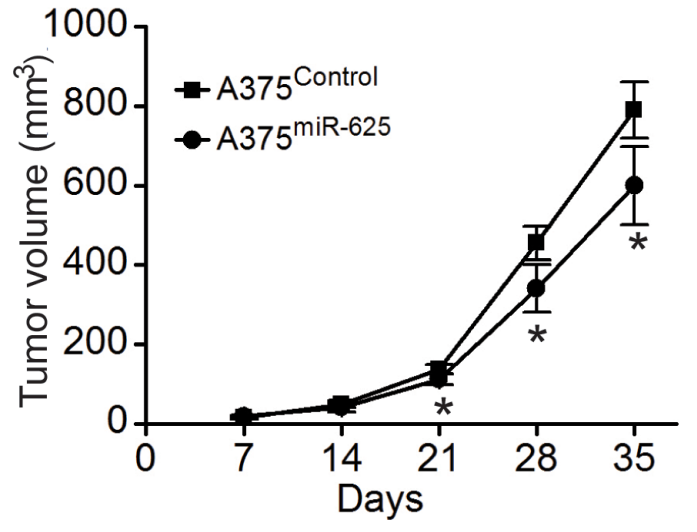

C

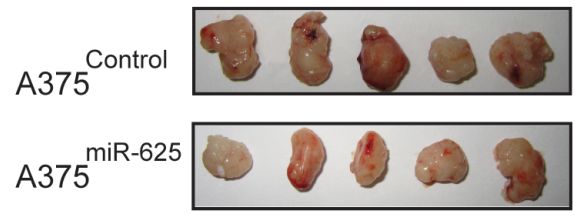

E

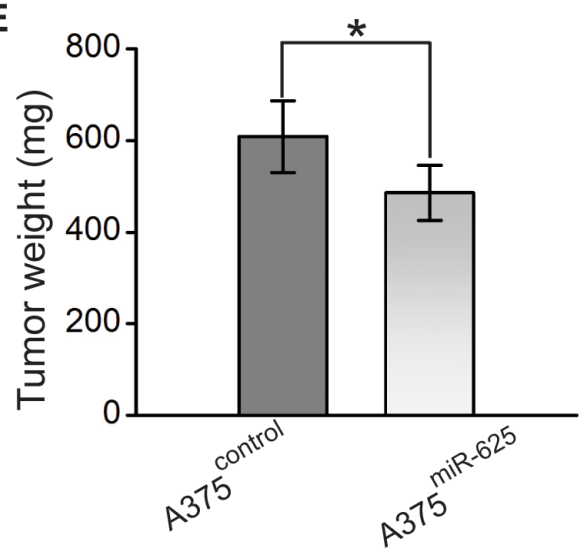

Figure 5: miR-625 inhibits tumorigenicity of malignant melanoma cells in vivo. A-C. Photographs of tumors derived for pSilencer-miR-Control or pSilencer-miR-625 stably transfected A375 cells in nude mice. D. Growth kinetics of tumors in nude mice. Tumor diameters were measured every 7 days $\left({ }^{*} P<0.05\right)$. E. Average weight of tumors in nude mice. Means \pm S.D. were shown $(* P<0.05)$. 
levels were inversely correlated with miR-625 levels in tissues (Figure 6D). Then we performed luciferase reporter assays to verify a direct interaction between miR-625 and the $3^{\prime} \mathrm{UTR}$ of $S O X 2$. Luciferase reporters were constructed with either a wild-type SOX2 3'UTR sequence that contained the miR-625 binding site (SOX2-3'UTR $\left.{ }^{\mathrm{wt}}\right)$ or a mutated 3'UTR (SOX2-3'UTR ${ }^{\text {mut }}$ ) (Figure 6E). The relative luciferase activity of the $S O X 2-3^{\prime} \mathrm{UTR}^{\mathrm{wt}}$ reporter was apparently suppressed by miR-625 mimics compared with that of SOX2-3' UTR $^{\text {mut }}$ in an miR-625-dependent manner (Figure 6F). This result strongly indicates that 3'UTR of $S O X 2$ carries the direct binding seed of miR-625, and miR-625 might target $S O X 2$ and inhibit its expression.

\section{$S O X 2$ can rescue effect of miR-625 in malignant melanoma cells}

Since $S O X 2$ is a potential target of miR-625, it is reasoned that ectopic of $S O X 2$ could rescue the biological phenotypes caused by miR-625 in malignant melanoma.

To verify this property, $S O X 2$ expressing plasmid or control plasmid was introduced into the A375 and M14 cells transiently transfected with miR-625 or control, and then cytological assays were performed to measure cell proliferation and migration. The results showed that ectopic expression of $S O X 2$ reversed the inhibitory effect of miR-625 on cell proliferation (Figure 7A and 7B)
A

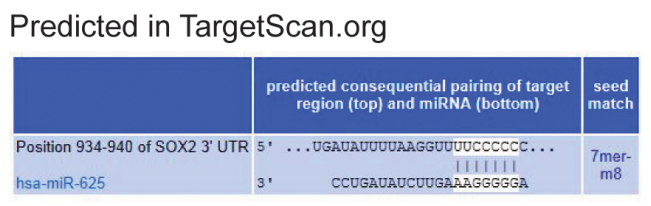

C

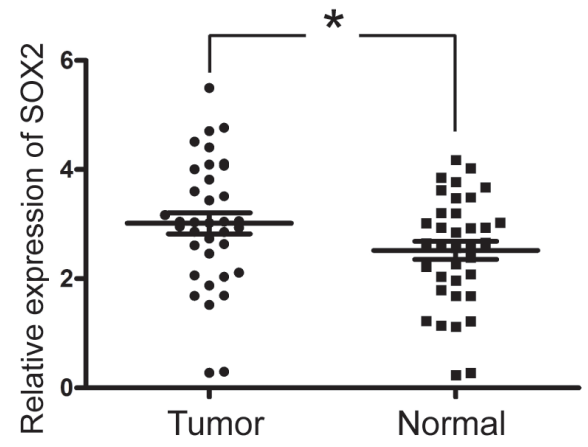

E

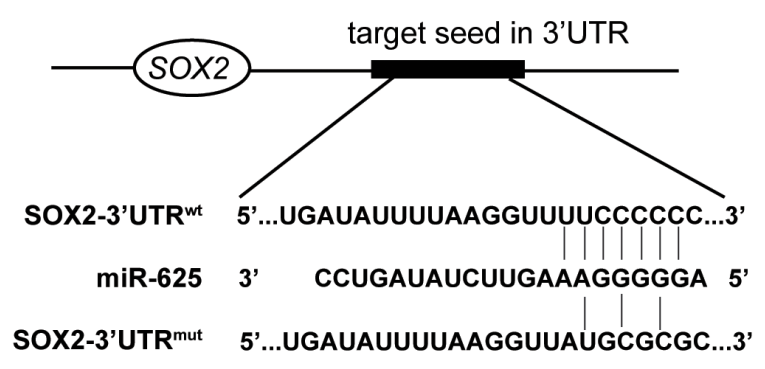

B

Predicted in microRNA. org
D

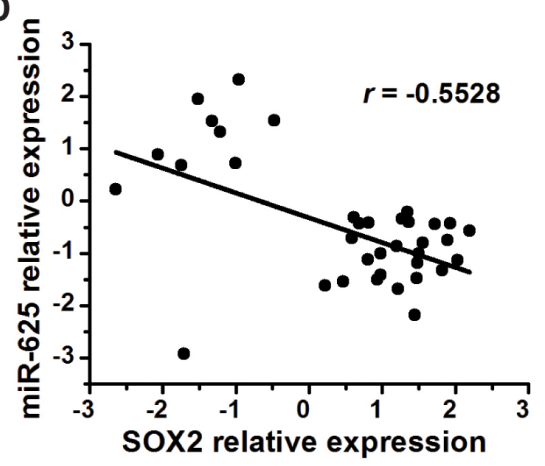

$\mathbf{F}$

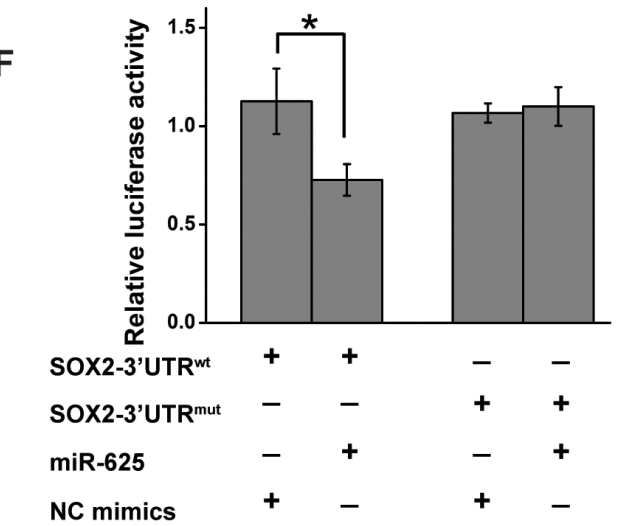

Figure 6: miR-625 targets the $3^{\prime}$-UTR of SOX2. A-B. The putative binding sites of miR-625 in the SOX2 $3^{\prime}$-UTR region were predicted by miRanda.org and TargetScan.org. The matched seed sequences are indicated by vertical lines. C. Relative expression of $S O X 2$ in malignant melanoma patients' tumor tissues compared with normal tissues. Data are shown as mean \pm SEM $(* P<0.05)$. D. Linear correlation analysis of SOX2 and miR-625 expression in melanoma samples. E. Schematic graph of the putative binding sites of miR-625 in the SOX2 3'UTR and the mutation in miR-625 binding sites. F. miR-625 mimics downregulated luciferase activities controlled by wildtype SOX2 3'UTR, but did not affect luciferase activity controlled by mutant SOX2 3'UTR. The results are means of three independent experiments \pm S.D. $(* P<0.05)$. 
A

\section{A375}

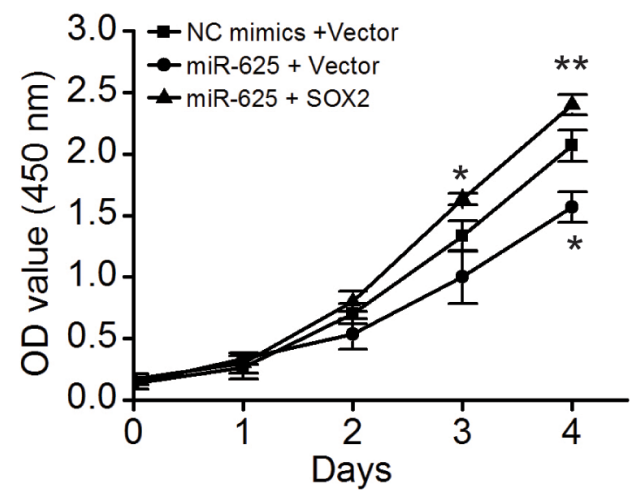

C

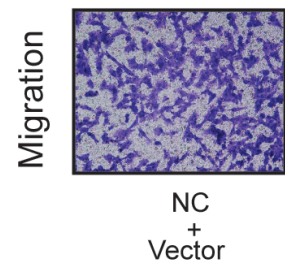

E

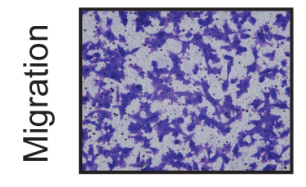

NC

Vector

G

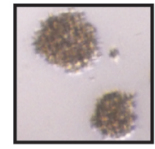

NC

Vector

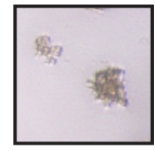

miR-625

Vector

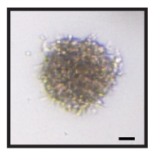

miR-625

SO๋ 2
A375

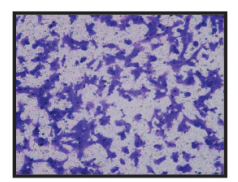

miR-625

Vector

M14

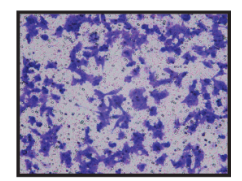

miR-625

Vector

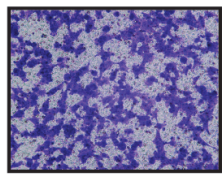

miR-625

SOX 2
M14

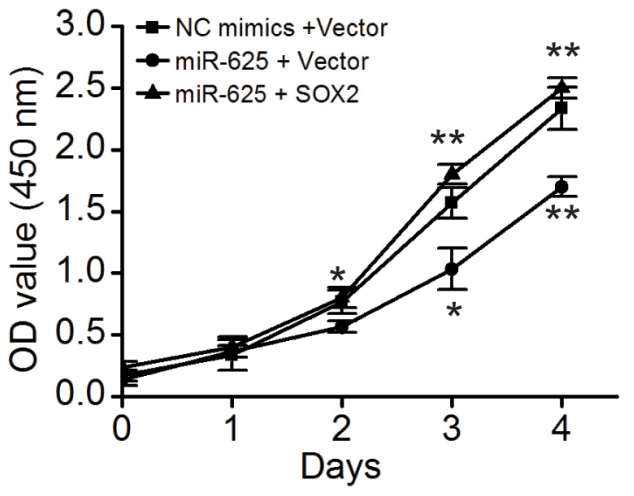

D

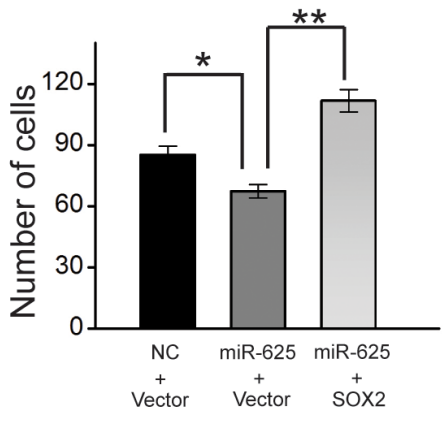

F

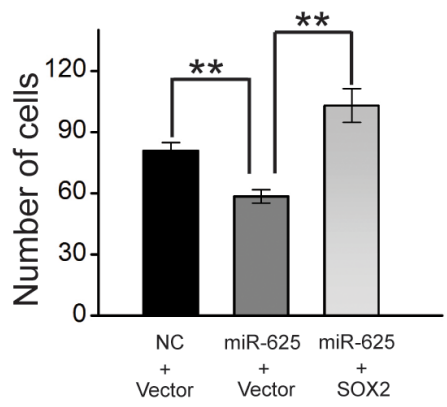

H

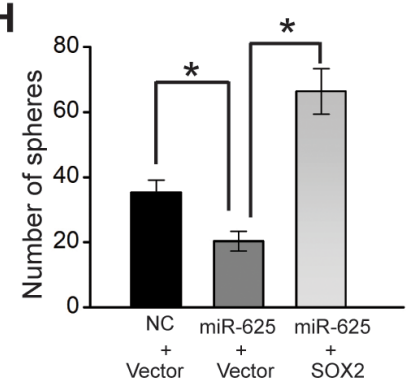

I

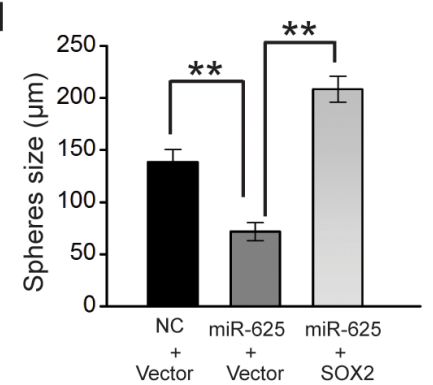

Figure 7: SOX2 can rescue effect of miR-625 in malignant melanoma. A. Cell proliferation was measured by the WST assay. A375 cells were transfected with miR-625 mimics, NC mimics, SOX2, or Vector control, at 24 hours after transfection. The WST assay was performed every 24 hours for 4 days. Results are means of three independent experiments \pm S.D. B. M14 cells were transfected with miR-625 mimics, NC mimics, anti-625, or anti-NC at a final concentration of $100 \mathrm{nM}$ and, at 24 hours after transfection. The WST assay was performed every 24 hours for 4 days. Results are means of three independent experiments \pm S.D. C. Representative photographs of migratory $\mathrm{A} 375^{\mathrm{NC} \text { mimics+Vector }}$, A375 ${ }^{\text {miR-625+Vector }}$, and A375 ${ }^{\text {miR-625+SOX2 }}$ cells on the membrane (magnification, 100 $\times$ ). D. Average number of migratory A375 cells. E. Representative photographs of migratory M14 ${ }^{\mathrm{NC} \text { mimics }+ \text { Vector }}$, M14 ${ }^{\text {miR-625+Vector }}$, and M14 ${ }^{\text {miR-625+Sox } 2}$ cells on the membrane (magnification, 100×). F. Average number of migratory M14 cells. The data represent the mean \pm S.D. of three independent experiments. G. Representative images of spheres as indicated. Scale bar $=50 \mu \mathrm{m}$. H. Average number of spheres. I. Measurement of the size of melanoma spheres. $(* P<0.05, * * P<0.01)$. 
and migration (Figure 7C-7F) in malignant melanoma. Moreover, $S O X 2$ rescued the effect of miR-625 on sphere formation, which is necessary for cell self-renewal (Figure 7E-7I). Thus, the data provide evidence that inhibition by miR-625 is at least partially related to the function of SOX2.

\section{DISCUSSION}

Evidence indicates that miRNAs have very important functions in many biological processes. It can no longer be considered "junk" as it previously had been [25]. In oncology research, miRNAs are shown to promote tumorigenesis and tumor progression.

Although the signatures of miRNAs in malignant melanoma have been well characterized, the functions of deregulated miRNAs in progression and development remain unclear. Deregulation of miR-625 has been reported in various cancers [12-16]. In these studies, the expression levels of miR-625 were significantly lower in tumor tissue or cells compared with corresponding normal tissue or cells, and miR-625 inhibits proliferation, invasion and tumorigenesis in vitro or in vivo, suggesting that it may serve as a tumor suppressor.

In the present study, we found that the expression of miR-625 decreased significantly in malignant melanoma tissue compared with the normal tissue. The data are consistent with reports in other tumors. Ectopic expression of miR-625 mimics suggested that miR-625 suppresses proliferation, wound healing, migration and invasion in malignant melanoma cells. The nude mouse subcutaneous tumor formation model confirmed that miR-625 inhibits the tumorgenicity in malignant melanoma cells in vivo, which is an important aspect of tumor progression.
miRNAs function as oncogenes or tumor suppressors by regulating their targets on the epigenetic level by decreasing translation of target mRNA or increasing degradation of target mRNA [26]. It has been reported that miR-625 targets HMGA1, SCAI, IGF2BP1, and ILK [12$16]$. We found that $S O X 2$ is a potential target of miR-625 in malignant melanoma. SOX2 is an embryonic stem cell transcription factor. It is an important factor in embryonic development and self-renewal in embryonic stem cells [27], and SOX2 is one of the determinate transcription factors capable of reprogramming differentiated somatic cells into induced pluripotent stem (iPS) cells [28, 29].

In the field of oncology research, $S O X 2$ functions as an oncogene in many types of tumors [30-32], including malignant melanoma. SOX2 inhibits apoptosis via MAP4K4-Survivin signaling in lung cancer cells [33] and promotes metastasis of breast and prostate cancer cells by promoting epithelial-to-mesenchymal transition via the WNT/ $\beta$-catenin signal network [34].

In previous studies, the expression of $S O X 2$ was upregulated in melanoma tissues and cells, and SOX2 invasion, self-renewal, and tumorigenicity of melanoma cells $[35,36]$. Our study shows that the expression level of miR-625 is inversely correlated with the expression profile of $S O X 2$, and $S O X 2$ reversed the inhibitory effect of miR-625 in malignant melanoma. The function of tumor suppressor miR-625 is at least partially related to targeting and repressing $S O X 2$, (Figure 8).

These findings suggest that miR-625/SOX2 is an important factor in malignant melanoma tumorigenesis. As a negative regulator of $S O X 2$, miR- 625 has potential value in precision medical therapy. The combination of protein gene and miRNA has emerged as a tool to predict the efficacy of treatment.

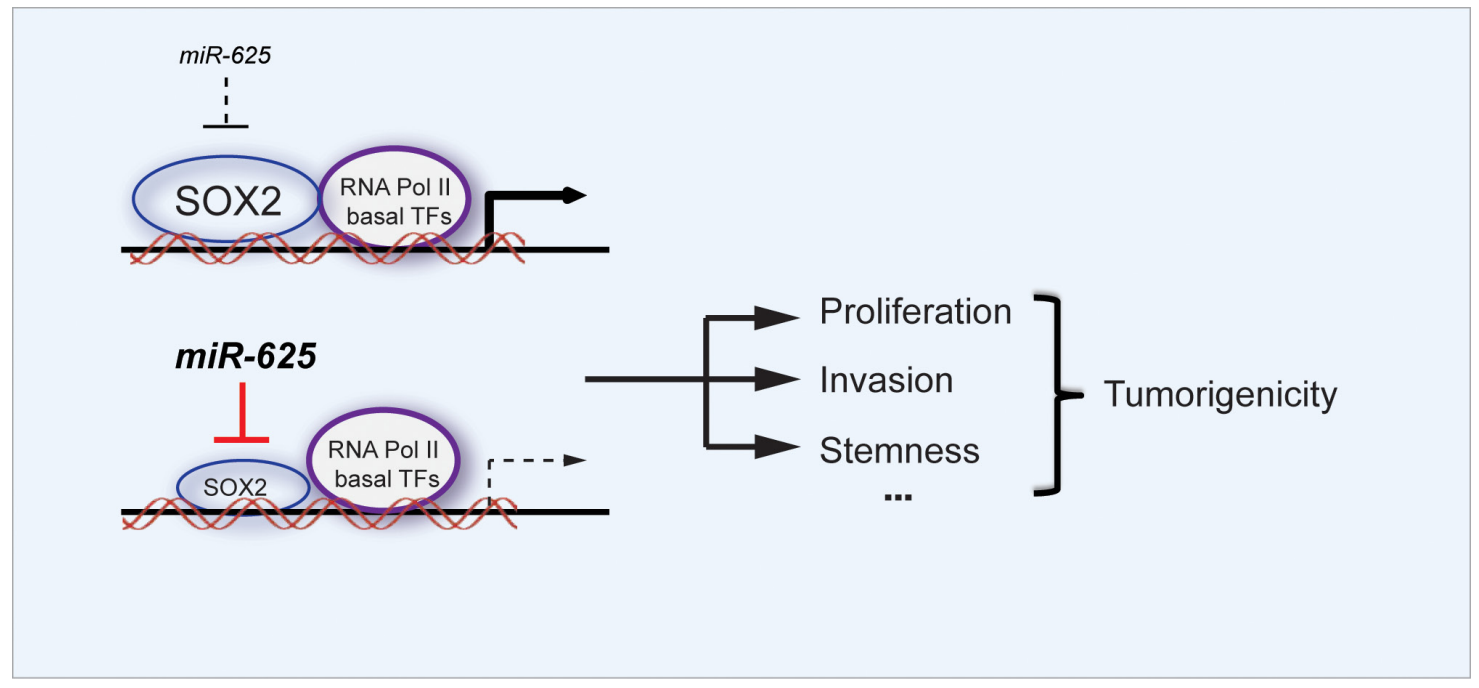

Figure 8: Schematic graph depicting the function of miR-625 in malignant melanoma. miR-625 inhibits proliferation, migration, and invasion in melanoma. The down-regulation of miR-625 removes the suppression of its target, $S O X 2$, leading to promotion of the tumorigenicity in malignant melanoma. 
Our data show that miR-625 is frequently downregulated in malignant melanoma. miR-625 suppresses the tumorgenicity and progression of malignant melanoma, suggesting that miR-625 will become a novel diagnostic marker and a new therapeutic target of malignant melanoma.

\section{MATERIALS AND METHODS}

\section{Ethics statement}

This work was approved by the Committee on Ethics of Biomedicine Research, Second Military Medical University. The animal studies were approved by the Committee on Ethics of Biomedicine Research, Second Military Medical University, and carried out in strict accordance with the recommendations in the Regulations for the Administration of Affairs concerning Experimental Animals of the State Science and Technology Commission. The animal model was established under isofluorane anesthesia, and all efforts were made to minimize animal suffering and distress.

\section{Cell culture}

Human malignant melanoma cell lines A375 and M14 were purchased from American Type Culture Collection (ATCC). A375 and M14 were cultured in RPMI-1640 Medium (Corning Cellgro ${ }^{\circledR}$, Manassas, VA, USA) with $10 \%$ fetal bovine serum (FBS) (Invitrogen, Carlsbad, CA, USA). Cells were maintained at $37^{\circ} \mathrm{C}$ with $5 \% \mathrm{CO}_{2}$ in a humidified incubator.

\section{RNA isolation and $q R T-P C R$}

Total RNA was extracted from tissues by use of a mirVana $^{\mathrm{TM}}$ miRNA Isolation Kit (Applied Biosystems, Foster City, CA, USA) per the manufacturer's instructions. Concentrations and purity of the RNA samples were measured by electrophoresis and spectrophotometric methods. The expression level of miR-625 in tissues was assayed by qRT-PCR and calculated.

\section{Transient transfection}

miR-625 mimics, negative control mimics, miR625 inhibitors (anti-miR-625) and inhibitor controls (antimiR-NC) were purchased from GenePharma (Shanghai, $\mathrm{Ch}$ ina). Cells were seeded into cell culture plates 20 hours before transfection to ensure $70 \%$ cell confluence at the moment of transfection. Transfection of oligonucleotides into malignant melanoma cells was carried out by use of Lipofectamine2000 (Invitrogen, Carlsbad, CA, USA) per the manufacturer's procedure. The oligonucleotides worked at the final concentration of $100 \mathrm{nM}$.

\section{Cell proliferation assay}

Cell proliferation was assessed by water-soluble tetrazolium salt (WST) assay with the Cell Counting Kit8 (Dojindo, Kumamoto, Japan) and measured per the manufacturer's instructions. At 24 hours after transfection with mimics or control mimics, malignant melanoma cells were seeded onto 96 -well plates $\left(2 \times 10^{3}\right.$ cells/well $)$, and cell proliferation was documented every 24 hours for 4 days. The number of viable cells was assessed by measurement of the absorbance at $450 \mathrm{~nm}$.

\section{Wound-healing assay}

Wound-healing assay was used to detect the capacity for cell motility. For scratch wound-healing assay, cells were cultured in serum-free medium for 24 hours and wounded with pipette tips. Fresh medium was replaced. The wound-closing procedure was observed for 36 hours and photographs were taken.

\section{Colony-formation assay}

In plate colony-formation assay, malignant melanoma cells were re-suspended in RPMI 1640 containing $10 \%$ FBS and layered onto 6-well plates $\left(5 \times 10^{2}\right.$ cells/well). The cells were incubated for 2 weeks and stained with crystal violet. Colonies containing 50 cells or more were counted.

\section{Cell migration and invasion assay}

Cell migration and invasion assay was performed by use of a transwell chamber ( $8 \mu \mathrm{m}, 24$-well insert; Corning, Lowell, MA, USA). In the migration assay, cells $\left(1 \times 10^{5}\right)$ in serum-free medium were added to the upper chamber, and medium containing $10 \%$ FBS were added to the lower chamber. Cells were then incubated for 24 hours. For the invasion assay, diluted Matrigel (BD Biosciences) was used to coat the membrane of the insert chambers. Cells were cultured for 48 hours under the same conditions. Finally, cells that migrated into or invaded the lower chambers were fixed with methanol, stained with crystal violet, and counted in six random fields.

\section{In vivo tumorigenesis}

SPF grade male BALB/c nude mice were purchased from the Institute of Zoology, Chinese Academy of Sciences. Malignant melanoma cells were re-suspended in $0.2 \mathrm{~mL}$ of RPMI 1640 and subcutaneously injected into 4 -week-old male nude mice $\left(2 \times 10^{6}\right.$ cells/mouse). The length (L) and width (W) of each tumor were measured every 7 days with calipers, and the volume was calculated by use of the formula $(\mathrm{W}+\mathrm{L}) / 2 \times \mathrm{W} \times \mathrm{L} \times 0.5236$. 


\section{Luciferase reporter activity assay}

The 293T cells were cultured in 24-well plates and transfected with $0.2 \mu \mathrm{g}$ of either wide-type or mutant $\mathrm{pMIR} / S O X 2$ plasmid containing firefly luciferase, together with $0.01 \mu \mathrm{g}$ of the pRL-TK vector (Promega, Wisconsin, USA) containing renilla luciferase and $1 \mu \mathrm{g}$ oligonucleotides. Transfection was performed by use of Lipofectamine2000 reagent (Invitrogen). Relative luciferase activity was calculated 36 hours after transfection by the Dual Luciferase Reporter Assay (Promega).

\section{Statistical analysis}

The differences between groups were analyzed by application of the Student $t$ test. All statistical analyses were performed by SPSS 15.0 software (SPSS Inc., Chicago, IL, USA), and $P<0.05$ was considered significant.

\section{CONFLICTS OF INTEREST} interests.

The authors declare that they have no competing

\section{GRANT SUPPORT}

This study was supported by grants from National Natural Science Foundation of China (No.81271799), the National Key Basic Research Programs of China (2013CB531604), and the Shanghai Municipal Natural Science Foundation (13JC1401401).

\section{REFERENCES}

1. Miller AJ, Mihm MC, Jr. Melanoma. The New England journal of medicine. 2006; 355:51-65.

2. Pacheco I, Buzea C, Tron V. Towards new therapeutic approaches for malignant melanoma. Expert reviews in molecular medicine. 2011; 13:e33.

3. Lujambio A, Lowe SW. The microcosmos of cancer. Nature. 2012; 482:347-355.

4. Bennett DC. How to make a melanoma: what do we know of the primary clonal events? Pigment cell \& melanoma research. 2008; 21:27-38.

5. Melnikova VO, Bar-Eli M. Transcriptional control of the melanoma malignant phenotype. Cancer biology \& therapy. 2008; 7:997-1003.

6. Ascierto PA, Grimaldi AM, Anderson AC, Bifulco C, Cochran A, Garbe C, Eggermont AM, Faries M, Ferrone S, Gershenwald JE, Gajewski TF, Halaban R, Hodi FS, Kefford R, Kirkwood JM, Larkin J, et al. Future perspectives in melanoma research: meeting report from the "Melanoma Bridge", Napoli, December 5th-8th 2013. Journal of translational medicine. 2014; 12:277.

7. O'Hara SP, Mott JL, Splinter PL, Gores GJ, LaRusso NF. MicroRNAs: key modulators of posttranscriptional gene expression. Gastroenterology. 2009; 136:17-25.

8. Bartel DP. MicroRNAs: genomics, biogenesis, mechanism, and function. Cell. 2004; 116:281-297.

9. Brueckner B, Stresemann C, Kuner R, Mund C, Musch T, Meister M, Sultmann H, Lyko F. The human let-7a-3 locus contains an epigenetically regulated microRNA gene with oncogenic function. Cancer research. 2007; 67:1419-1423.

10. Gupta GP, Massague J. Cancer metastasis: building a framework. Cell. 2006; 127:679-695.

11. Esquela-Kerscher A, Slack FJ. Oncomirs - microRNAs with a role in cancer. Nature reviews Cancer. 2006; 6:259-269.

12. Zhou WB, Zhong CN, Luo XP, Zhang YY, Zhang GY, Zhou DX, Liu LP. miR-625 suppresses cell proliferation and migration by targeting HMGA1 in breast cancer. Biochemical and biophysical research communications. 2016; 470:838-844.

13. Zheng H, Ma R, Wang Q, Zhang P, Li D, Wang Q, Wang J, Li H, Liu H, Wang Z. MiR-625-3p promotes cell migration and invasion via inhibition of SCAI in colorectal carcinoma cells. Oncotarget. 2015; 6:27805-27815. doi: 10.18632/ oncotarget. 4738 .

14. Zhou X, Zhang CZ, Lu SX, Chen GG, Li LZ, Liu LL, Yi C, Fu J, Hu W, Wen JM, Yun JP. miR-625 suppresses tumour migration and invasion by targeting IGF2BP1 in hepatocellular carcinoma. Oncogene. 2015; 34:965-977.

15. Li C, Li DC, Che SS, Ma K, Wang YJ, Xia LH, Dai XM, Zhang GT, Shen Y, Jiao WJ, Tian KH. The decreased expression of miR-625 predicts poor prognosis of esophageal squamous cell carcinoma. International journal of clinical and experimental medicine. 2015; 8:9560-9564.

16. Wang M, Li C, Nie H, Lv X, Qu Y, Yu B, Su L, Li J, Chen X, Ju J, Yu Y, Yan M, Gu Q, Zhu Z, Liu B. Downregulated miR-625 suppresses invasion and metastasis of gastric cancer by targeting ILK. FEBS letters. 2012; 586:2382-2388.

17. Mueller DW, Rehli M, Bosserhoff AK. miRNA expression profiling in melanocytes and melanoma cell lines reveals miRNAs associated with formation and progression of malignant melanoma. The Journal of investigative dermatology. 2009; 129:1740-1751.

18. Roth C, Stuckrath I, Pantel K, Izbicki JR, Tachezy M, Schwarzenbach H. Low levels of cell-free circulating miR-361-3p and miR-625* as blood-based markers for discriminating malignant from benign lung tumors. PloS one. 2012; 7:e38248.

19. Robinson JL, Hickey TE, Warren AY, Vowler SL, Carroll T, Lamb AD, Papoutsoglou N, Neal DE, Tilley WD, Carroll JS. Elevated levels of FOXA1 facilitate androgen receptor chromatin binding resulting in a CRPC-like phenotype. Oncogene. 2014; 33:5666-5674. 
20. John B, Enright AJ, Aravin A, Tuschl T, Sander C, Marks DS. Human MicroRNA targets. PLoS biology. 2004; 2:e363.

21. Lewis BP, Shih IH, Jones-Rhoades MW, Bartel DP, Burge CB. Prediction of mammalian microRNA targets. Cell. 2003; 115:787-798.

22. Kruger J, Rehmsmeier M. RNAhybrid: microRNA target prediction easy, fast and flexible. Nucleic acids research. 2006; 34:W451-454.

23. Betel D, Wilson M, Gabow A, Marks DS, Sander C. The microRNA.org resource: targets and expression. Nucleic acids research. 2008; 36:D149-153.

24. Rehmsmeier M, Steffen P, Hochsmann M, Giegerich R. Fast and effective prediction of microRNA/target duplexes. Rna. 2004; 10:1507-1517.

25. Berg P. Origins of the human genome project: why sequence the human genome when $96 \%$ of it is junk? American journal of human genetics. 2006; 79:603-605.

26. Breving K, Esquela-Kerscher A. The complexities of microRNA regulation: mirandering around the rules. The international journal of biochemistry \& cell biology. 2010; 42:1316-1329.

27. Avilion AA, Nicolis SK, Pevny LH, Perez L, Vivian $\mathrm{N}$, Lovell-Badge R. Multipotent cell lineages in early mouse development depend on SOX2 function. Genes \& development. 2003; 17:126-140.

28. Takahashi K, Tanabe K, Ohnuki M, Narita M, Ichisaka T, Tomoda K, Yamanaka S. Induction of pluripotent stem cells from adult human fibroblasts by defined factors. Cell. 2007; 131:861-872.

29. Yu J, Vodyanik MA, Smuga-Otto K, Antosiewicz-Bourget J, Frane JL, Tian S, Nie J, Jonsdottir GA, Ruotti V, Stewart R, Slukvin, II, Thomson JA. Induced pluripotent stem cell lines derived from human somatic cells. Science. 2007; 318:1917-1920.
30. Leis O, Eguiara A, Lopez-Arribillaga E, Alberdi MJ, Hernandez-Garcia S, Elorriaga K, Pandiella A, Rezola $\mathrm{R}$, Martin AG. Sox 2 expression in breast tumours and activation in breast cancer stem cells. Oncogene. 2012; 31:1354-1365.

31. Chou YT, Lee CC, Hsiao SH, Lin SE, Lin SC, Chung CH, Chung CH, Kao YR, Wang YH, Chen CT, Wei YH, Wu $\mathrm{CW}$. The emerging role of SOX2 in cell proliferation and survival and its crosstalk with oncogenic signaling in lung cancer. Stem cells. 2013; 31:2607-2619.

32. Basu-Roy U, Seo E, Ramanathapuram L, Rapp TB, Perry JA, Orkin SH, Mansukhani A, Basilico C. Sox2 maintains self renewal of tumor-initiating cells in osteosarcomas. Oncogene. 2012; 31:2270-2282.

33. Chen S, Li X, Lu D, Xu Y, Mou W, Wang L, Chen Y, Liu Y, Li X, Li LY, Liu L, Stupack D, Reisfeld RA, Xiang $\mathrm{R}$, Li N. SOX2 regulates apoptosis through MAP4K4survivin signaling pathway in human lung cancer cells. Carcinogenesis. 2014; 35:613-623.

34. Li X, Xu Y, Chen Y, Chen S, Jia X, Sun T, Liu Y, Li X, Xiang $\mathrm{R}, \mathrm{Li}$ N. SOX2 promotes tumor metastasis by stimulating epithelial-to-mesenchymal transition via regulation of WNT/beta-catenin signal network. Cancer letters. 2013; 336:379-389.

35. Santini R, Pietrobono S, Pandolfi S, Montagnani V, D'Amico M, Penachioni JY, Vinci MC, Borgognoni L, Stecca B. SOX2 regulates self-renewal and tumorigenicity of human melanoma-initiating cells. Oncogene. 2014; 33:4697-4708.

36. Girouard SD, Laga AC, Mihm MC, Scolyer RA, Thompson JF, Zhan Q, Widlund HR, Lee CW, Murphy GF. SOX2 contributes to melanoma cell invasion. Laboratory investigation; a journal of technical methods and pathology. 2012; 92:362-370. 